\title{
Motivational vs. associative role of the US in classical conditioning of the rabbit's nictitating membrane response
}

\author{
FRED K. HOEHLER \\ Department of Physical Medicine and Rehabilitation, University of California, Irvine, California 92668
}

and

DALE W. LEONARD

Department of Psychological Sciences, Purdue University, Lafayette, Indiana 47907

\begin{abstract}
Two experiments tested the motivational role of the US in classical conditioning of the rabbit's nictitating membrane (NM) response. In Experiment 1, subjects were trained to an intermediate performance level and then given a series of (1) CS-US trials, (2) "backwards" US-CS trials, (3) CS-alone trials, (4) US-alone trials, or (5) no-stimulus presentations. Interpolated presentations of the US, either alone or in a backwards contingency, tended to produce an impairment of subsequent acquisition. In Experiment 2, subjects were trained with strong or weak US intensity on paired or interpolated trials. US intensity on interpolated trials had only a very small effect, whereas the effect of US intensity on paired trials was quite large. Shifts in paired-trial US intensity produced corresponding shifts in performance, but shifts in the intensity of the interpolated US produced no apparent effect. We conclude that the arousal of motivation is not sufficient to maintain performance in classical NM conditioning.
\end{abstract}

The role of the US in classical conditioning is fundamentally ambiguous. In conditioning of the rabbit's nictitating membrane (NM) response, as in most Pavlovian paradigms, US intensity is an extremely powerful variable (e.g., Hoehler, Kirschenbaum, \& Leonard, 1973; Smith, 1968). However, the mechanism of these effects in not entirely clear. Changes in US intensity, US quality (e.g., Bruner, 1965), or US location (e.g., Salafia, Daston, Bartosiak, Hurley, \& Martino, 1974) will simultaneously affect both associative and motivational features of the conditioning situation, and the two are, sometimes, quite difficult to separate. By definition, associative factors are critical for classical conditioning, and, in fact, studies of the CS-US interval have clearly demonstrated the importance of temporal contiguity (e.g., Gormezano, 1972; Hoehler \& Thompson, 1980; Smith, 1968). The role of motivation is somewhat less well established. Bruner (1966) and Frey, Maisiak, and Dugue (1976) have shown that presentation of reinforcing brain stimulation during the US tends to facilitate conditioning. However, Martin, Land, and Thompson (1980) have demonstrated that direct electrical stimulation of motoneurons in abducens (6th nerve) nucleus

The authors would like to thank Lewis C. Fischbein and Joyce C. Monteau for their help with the collection and analysis of data. Reprint requests should be sent to Fred K. Hoehler, Department of Physical Medicine and Rehabilitation, University of California Irvine Medical Center, 101 City Drive South, Orange, California 92668. can serve as a US for NM extension. Thus, motivation may be unnecessary for NM conditioning.

The role of motivation in classical conditioning may also be investigated using interpolated presentations of the US. This method is based on the presumption that motivational effects of the US do not depend on CS-US pairing but will occur with equal strength if the US is presented alone. Two important studies in the human eyelid-conditioning literature have shown that (1) after a few CS-US trials, a series of interpolated USs may produce a performance increase comparable to that produced by continued CS-US pairing (Kimble, Mann, \& Dufort, 1955), and (2) interpolated presentation of a high-intensity US may prevent the performance decline that normally results from a reduction in US intensity (Trapold \& Spence, 1960). These studies suggested that motivation is extremely important for both the acquisition and the maintenance of classical CRs. In the studies to be reported here, the above-mentioned experimental paradigms were extended to classical conditioning of the rabbit's NM response.

\section{EXPERIMENT 1}

The first paradigm was originated by Kimble et al. (1955), who reported an experiment indicating that the first few CS-US pairings were sufficient for the formation of the associations necessary for eyelid conditioning and that, beyond this point, presenta- 
tions of the US alone were as efficient as CS-US pairings in improving performance. The basic experimental design consisted of training a group of subjects to an intermediate level of performance, and then presenting a series of US-alone trials followed by a final series of CS-US pairings. The performance of this experimental group was found to be virtually identical to the performance of a group of control subjects given only CS-US pairings. This finding was offered as evidence for two distinct processes in eyelid conditioning: (1) an associative process that depends upon the contingency of CS-US pairings, and (2) a performance factor linked to motivational processes determined by the US. A further implication drawn from this experiment was that "pseudoconditioning may be a part of all conditioning in which a noxious stimulus is employed" (Kimble, 1961, p. 62).

These unusual data did not meet with uncritical acceptance. The effect was replicated and extended in a follow-up study by Kimble and Dufort (1956), but another replication attempt by Goodrich, Ross, and Wagner (1957) found that an interpolated series of US-alone presentations had no effect on performance. Dufort and Kimble (1958) again replicated the effect and attributed the discrepancy to the presence or absence of a "ready signal." Unfortunately, Goodrich, Ross, and Wagner (1959) failed to find the effect with or without a ready signal. Several successful (Kimble \& Ost, 1961; Loess, 1964) and unsuccessful (Grant, McFarling, \& Gormezano, 1960; McAllister, 1960) replication attempts can be found in the later literature, but the controversy has never been resolved. In the present experiment, we examined the performance of five groups of rabbits receiving an interpolated series of (1) US-alone presentations, (2) continued CS-US pairing, (3) CS-alone presentations, (4) backward US-CS pairing, or (5) no stimulation.

\section{Method}

The apparatus and procedure used for rabbit NM conditioning have previously been described (Hoehler et al., 1973). The subjects were 80 albino New Zealand rabbits, $1.5-3.0 \mathrm{~kg}$, obtained from a local supplier. During conditioning, they were restrained in Plexiglas boxes with adjustable head stocks and padded ear clamps (see Gormezano, 1966, p. 407). A small loop of monofilament nylon was sutured into the $\mathrm{NM}$, and a miniature precision rotary potentiometer was mounted on the subject's head, by means of a lightweight muzzle, and mechanically attached to the NM suture. Thus, NM extension created a voltage change that was amplified and recorded by a polygraph with amplification adjusted so that the UR produced a pen deflection of approximately $15-20 \mathrm{~mm}$. A pen deflection of $1 \mathrm{~mm}$ or more, initiated 100 250 msec after CS onset, was scored as a CR.

The subjects were conditioned four at a time in identical soundattenuation chambers, each equipped with a blower system for ventilation and a light for illumination. The CS was a $250-\mathrm{msec}$, $1,000-\mathrm{Hz}, 85-\mathrm{dB}$ tone, while the US was a $10-\mathrm{msec}, 10-\mathrm{mA} \mathrm{dc}$ electric shock delivered via stainless steel subcutaneous electrodes located above and below the right eye. Offset of the CS and on- set of the US were simultaneous during regular conditioning trials, and offset of the US and onset of the CS were simultaneous during the backward-conditioning trials. The intertrial interval was approximately $60 \mathrm{sec}$. Presentation and timing of all stimuli were automatically controlled by a Digital PDP-8/S computer interfaced for that purpose.

Data were collected during a single conditioning session, consisting of three consecutive phases. In the first phase, five randomly selected groups of 16 rabbits each received 50 CS-US pairings, bringing each group to an intermediate level of performance. In Phase 2, which followed Phase 1 without interruption, three experimental groups received a series of 40 trials of various types. Group US received 40 presentations of US alone, Group BK received $\mathbf{4 0}$ backwards US-CS pairings, and Group CS received $40 \mathrm{CS}$-alone extinction trials. Two control groups were employed: Group C, which continued to receive CS-US pairings, and Group $R$, which merely "rested" for $40 \mathrm{~min}$. In Phase 3 (90 trials), normal conditioning, identical to Phase 1 , was resumed. Thus, all groups received a total of 140 reinforced trials, with the three experimental groups receiving $\mathbf{4 0}$ additional trials of interpolated stimuli.

\section{Results and Discussion}

As shown in Figure 1, interpolated US-alone trials did not facilitate performance but, rather, appeared to produce a substantial impairment of subsequent acquisition. The percentage of CRs on the first block

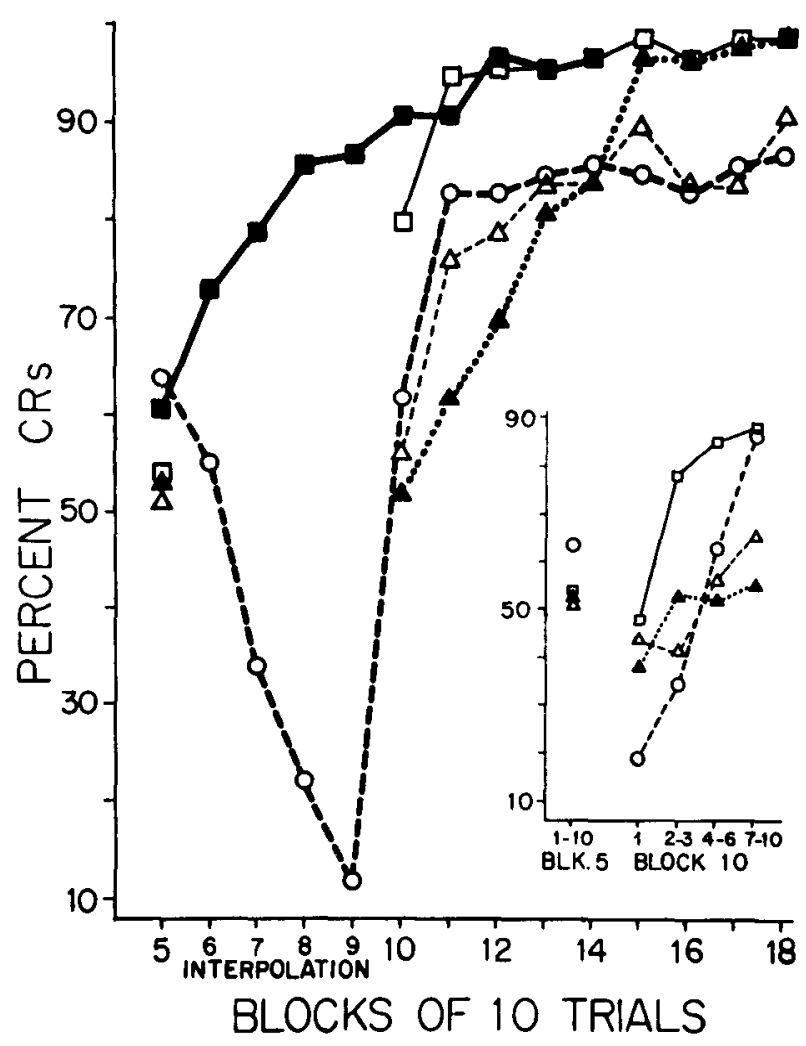

Figure 1. The effect of various interpolated stimuli (Blocks 6-9) in Experiment 1. Filled squares: continued CS-US pairings (Group C). Open squares: $\mathbf{4 0} \mathrm{min}$ of no stimulation (Group R). Filled triangles: 40 presentations of US alone (Group US). Open triangles: 40 presentations of backward CS-US pairings (Group BK). Open circles: 40 presentations of CS alone (Group CS). 
of 10 trials following interpolation revealed a significant difference between groups $[F(4,75)=3.77$, $\mathrm{p}<.01]$. Duncan's range test comparisons indicated that Group $C$ was superior to Group US (the equivalent of Kimble's experimental group), as well as to Groups BK and CS, but that Group C was not superior to Group R. In addition, Group $R$ was found to be superior to Group US. Mean CR amplitudes (as a proportion of UR amplitude) were .54 in Group C, .30 in Group R, .40 in Group US, .26 in Group BK, and .29 in Group CS. There was a significant difference between groups $[F(4,64)=3.54, p<.05]$, and Group C was superior to Groups $R$, US, and BK. Note that, in Group US, six subjects produced no CRs and, hence, were not included in the averaged CR amplitude data. No other group contained more than three subjects that produced no CRs.

The performance of Group $\mathrm{R}$ and the three experimental groups on Block 10 does, of course, reflect the incremental effect of the 10 CS-US trials within that block. To examine these performance changes in greater detail, the inset of Figure 1 shows Block 10 performance divided into smaller segments. It is apparent that all groups started Block 10 at a lower performance level than before interpolation, but that the rate of recovery in Groups CS and $\mathrm{R}$, which received no shock during the interpolation phase, was faster than the rate of recovery of Groups US and BK, both of which did receive shock during interpolation. A Mann-Whitney $U$ test revealed that difference scores (obtained by subtracting percent CRs on Trials 1-3 from percent CRs on Trials 8-10) were significantly higher in the unshocked (CS and $R$ ) groups $(U=297, p<.001)$. Further confirmation of this impression was found by comparing the performance of the combined shocked groups with the combined unshocked groups on Trials 7-10 of Block 10. Again, the unshocked groups were significantly superior to the shocked groups $(U=355, \mathrm{p}<.01)$.

We conclude that, in this conditioning preparation, interpolated presentations of the US exert, at best, a neutral effect, and, at worst, a negative effect on the conditioning process. The performance of the "rest" group (Group R) is consistent with recent evidence that rabbits condition fastest with 24-h intertrial intervals (e.g., Levinthal, 1973) or that, during multipletrial conditioning sessions, the greatest gains are generally observed between, rather than within, days (Frey \& Gavin, 1975).

\section{EXPERIMENT 2}

The next paradigm to be considered originated from the laboratories of the late Kenneth $W$. Spence and, along with his work on manifest anxiety, constitutes what is perhaps his most important contribution to the classical conditioning literature.

Spence set out to determine whether or not the intensity of the US was a factor in determining the strength of the associative bond linking stimulus and response, as opposed to the notion that variations in US intensity contribute only to the motivational state of the organism. The problem was to hold the motivational effects of the US constant, while examining habit growth under high or low US intensities. An early experiment (Spence, 1953) employed a factorial design in which conditioning was carried out under high or low intensities on Day 1 and under the same or opposite intensities on Day 2. While the significant effect of Day 1 US intensity on Day 2 performance suggested to Spence that associative bonds established on Day 1 "carried over" to Day 2 performance, such a design is difficult to interpret, since the results are jointly determined by the rate of change of the postshift performance and the precise portion of the performance curve selected for evaluation and analysis.

Spence's eventual solution to this problem was to vary US intensity on CS-US paired trials (trials during which associative strength was hypothetically being generated) and to counterbalance the motivational effects of a given US intensity by randomly interspersing US-alone trials of the opposite intensity. Thus, two basic groups were generated: one which received CS-US pairings at a strong US intensity in conjunction with US alone at a weak intensity (the strong-weak condition) and another which received the weak US on paired trials along with strong US alone (the weak-strong condition). The superior performance of the strong-weak (SW) group relative to the weak-strong (WS) group would implicate an associative factor, since motivation would be equated, and several experiments (e.g., Spence, Haggard, \& Ross, 1958; Trapold \& Spence, 1960) produced such a result.

As a further test of the hypothesis that associative strength was a direct function of US intensity in classical conditioning, it was proposed that, after asymptotic levels of conditioning had been attained, a shift in US intensity from strong to weak, with motivational levels again equated, should have little or no decremental effect on performance. This prediction stemmed from Hull's (1943) assertion that association, or habit strength, was a relatively permanent factor. In a study reported by Trapold and Spence (1960), the SW group outperformed the WS group in Phase 1 of the experiment, and a shift from SW to WS in Phase 2 resulted in only a slight, nonsignificant decrement in performance. In contrast, a substantial performance decrement was produced by a shift from SW to a weak-weak (WW) condition. On the basis of these results, Spence argued that habit strength built up in Phase 1 might sustain performance in the second phase when factors favorable to further habit growth were removed.

Experiment 2 was based on the design employed by Trapold and Spence (1960). In addition to the groups mentioned above, Experiment 2 contained (1) a group that received a shift to a higher US in- 
tensity on paired trials (WS-SW), (2) two groups necessary for a complete factorial analysis of the effects of US intensity on paired and interpolated trials (SS and WW), and (3) a group that was shifted to a low-intensity interpolated US (WS-WW).

\section{Method}

The general methods were similar to those employed in Experiment 1 . The US was a $10-\mathrm{msec}$ pulse of electric shock at either a strong $(6.5 \mathrm{~mA})$ or a weak $(1.8 \mathrm{~mA})$ intensity.

In Phase 1, four groups of rabbits received strong (S) or weak (W) shocks alone or paired with the $\mathrm{CS}$ in a 2 by 2 factorial design. The four groups may be designated as $\mathrm{SS}(\mathrm{N}=8), \mathrm{SW}(\mathrm{N}=$ 24), WS $(N=24)$, and $W W(N=8)$, with the first letter indicating the intensity of the US on paired CS-US trials and the second letter indicating the intensity on US-alone trials. All subjects received an irregular sequence of $120 \mathrm{CS}-\mathrm{US}$ trials and $120 \mathrm{US}$ alone trials in Phase 1. The intertrial interval had a mean of $20 \mathrm{sec}$ (range $=15-25 \mathrm{sec}$ ), so that the interval between CS-US trials averaged $40 \mathrm{sec}$.

In Phase 2, all groups received an additional 120 CS-US pairings and 120 US-alone trials, but the subjects in Groups SW and WS were (1) shifted to the opposite schedule (SW or WS), (2) shifted to WW, or (3) continued under the same conditions as in Phase 1. Groups SS and WW were not shifted in Phase 2. Thus, there were eight groups of eight subjects each, including four unshifted control groups (SS, SW, WS, WW) and four shift groups designated by the following Phase 1 and Phase 2 schedules: SW-WS, and SWWW, WS-SW, and WS-WW.

\section{Results and Discussion}

Table 1 shows percent $C R s$ and $C R$ amplitude in blocks of 60 reinforced trials during both the preshift postshift phases of Experiment 2. From an examination of the four control groups (SS, SW, WS, and WW), it is clear that the critical factor determining both the rate of acquisition and the asymptotic CR percentage was the intensity of the US on paired (CSUS) trials. A 2 by 2 by 4 factorial analysis of variance, with two levels of US intensity on paired trials, two levels of interpolated US intensity, and four blocks of 60 trials, indicated significant effects of pairedtrial US intensity $[F(1,28)=114.9, p<.001]$ and trial blocks $[F(3,84)=76.3, p<.001]$. Also significant were the interactions of trial blocks with paired-trial US intensity $[F(3,84)=23.1, p<.001]$ and interpolated US intensity $[F(3,84)=4.35, p<.01]$, but no other effects approached statistical significance. A similar pattern was observed in the CR amplitude data.

The fact that the strength of conditioning is determined primarily by the intensity of the US paired with the CS is consistent with findings from the human eyelid conditioning literature and is in agreement with Spence's hypothesis that associative strength is a direct function of US intersity. It might also be noted that the facilitatory effect exerted by the more intense US-alone trials runs counter to the notion that interpolated USs interfere with conditioning by disrupting consolidation processes (e.g., Grevert \& Moore, 1970). If the more intense US-alone trial did, in fact, produce greater disruption of consolidation, this negative effect must have been outweighed by positive motivational factors. It has also been suggested that interpolated US-alone trials may impair conditioning through disruption of the CS-US contingency (e.g., Leonard, Fischbein, \& Monteau, 1972). This hypothesis implies that conditioning should be more impaired when the interpolated US is identical to the paired US. That is, there should be a significant interaction between paired and unpaired US intensity. Although this interaction appeared to be present, it was not statistically significant $[F(1,28)=2.55$, $\mathrm{p}>.10]$.

The effect of US-intensity shifts was assessed by examination of the groups labeled SW, SW-WS, WS, and WS-SW. A 2 by 2 factorial analysis of variance, with Phase 1 US intensity as one factor and Phase 2 US intensity as the other, indicated that, during the first half of Phase 2 (Trials 121-180), the effect of Phase 1 US intensity predominated $[F(1,28)=18.49$, $\mathrm{p}<.001$ ], while the effect of Phase 2 US intensity was not significant $[F(1,28)=3.31, p>.05]$. A similar analysis performed on the last half of Phase 2 (Trials 181-240) revealed a complete reversal in which Phase 2 US intensity was significant $[F(1,28)=23.65, p<.001]$ and the effect of Phase 1 US intensity was not $[F(1,28)$ $=1.20, \mathrm{p}>.10 \mathrm{]}$. There were no significant interactions between the effects of Phase 1 and Phase 2 US intensities [Fs $(1,28) \leqslant 1.77$, ps $>.10]$. If CR percentage scores are examined in blocks of 10 trials,

Table 1

Percent CRs and CR Amplitude as a Function of the Intensity of Paired and Interpolated Shock (Experiment 2)

\begin{tabular}{|c|c|c|c|c|c|c|}
\hline \multirow[b]{3}{*}{ Group } & \multirow{3}{*}{$\begin{array}{c}\text { Phase } 1 \\
(61-120)\end{array}$} & \multicolumn{2}{|c|}{ Percent CRs } & \multicolumn{3}{|c|}{ CR Amplitude (in Millimeters) } \\
\hline & & & & \multirow{2}{*}{$\begin{array}{c}\text { Phase } 1 \\
(61-120) \\
\end{array}$} & \multicolumn{2}{|c|}{ Phase 2} \\
\hline & & $121-180$ & $181-240$ & & $121-180$ & $181-240$ \\
\hline SS & 79 & 92 & 95 & 5.1 & 7.2 & 7.8 \\
\hline SW & 85 & 92 & 94 & 6.2 & 6.9 & 7.6 \\
\hline SW-WS & 89 & 83 & 64 & 6.2 & 6.7 & 3.0 \\
\hline SW-WW & 85 & 72 & 64 & 5.9 & 4.4 & 2.2 \\
\hline WS-SW & 13 & 58 & 94 & $1.3^{*}$ & 3.3 & 6.3 \\
\hline WS & 8 & 32 & 41 & $1.4^{*}$ & $1.9 *$ & $3.7 *$ \\
\hline WS-WW & 25 & 34 & 51 & $1.3^{*}$ & $1.4^{*}$ & $1.7^{*}$ \\
\hline WW & 5 & 8 & 15 & $1.3^{*}$ & $1.1^{*}$ & $1.1^{*}$ \\
\hline
\end{tabular}


the crossover in group mean performance curves occurs between Postshift Blocks 5 and 6. Group SWWS produced $81 \%$ CRs on Block 5 and $64 \%$ CRs on Block 6, while Group WS-SW produced 63\% CRs on Block 5 and $95 \%$ CRs on Block 6 . These shifts in performance cannot be ascribed to a general motivational factor, because all four groups in this comparison received identical levels of averaged shock intensity. The relatively minor role of strictly motivational factors is also indicated by the performance of two groups shifted to a lower average level of shock intensity in Phase 2. These groups (SW-WW and WS-WW) were clearly not inferior to comparable groups in which the general motivational level was maintained (SW-WS and WS). It is apparent that the intensity of the paired US exerts a powerful and fairly rapid effect on performance and that effect is not attributable to differences in the general level of motivation.

\section{GENERAL DISCUSSION}

These experiments have investigated two experimental procedures which tested the motivational role of the US in human eyelid conditioning. Kimble et al. (1955) reported that, after conditioning to an intermediate level of performance, a series of US-alone trials produced an increase in performance levels equivalent to that produced by continued pairing of CS and US. Trapold and Spence (1960) reported that the interpolation of high-intensity US-alone trials was sufficient to prevent the decline in performance normally associated with shifts in US intensity on CSUS trials. These data implied that, after the first few CS-US pairings, the association is completely and, more or less, permanently learned and that subsequent changes in performance are primarily due to changes in motivation. Our data imply a much smaller role for generalized motivational factors in classical conditioning of the rabbit's NM response. In Experiment 1 , a series of US-alone presentations actually produced a decrease in subsequent performance. This decrement may result from the same factors responsible for the impairment of acquisition produced by US presentations interspersed throughout acquisition (Grevert \& Moore, 1970; Leonard et al., 1972) or presented prior to initial training (Mis \& Moore, 1973). Because impairments occurred when the US was presented (Group BK and Group US) but not when the CS was presented alone (Group CS), the most reasonable explanation would seem to involve some form of habituation to the US, rather than a specific disruption of the CS-US contingency. The rapid recovery of the group that received CS-alone trials is consistent with the notion that CS-alone extinction procedures are relatively ineffective in inhibiting the associative connection between the CS and the US (Frey \& Butler, 1977). In Experiment 2, the intensity of the interpolated US did tend to affect acquisition, but the addition of interpolated USs sufficient to maintain the average US-intensity level was not sufficient to prevent the decline in performance produced by reduction of US intensity on paired trials. These data suggest that the role of the US, in the formation of a generalized motivational state, is not particularly important for classical conditioning of the rabbit's NM response.

\section{REFERENCES}

Bruner, A. UCS properties in classical conditioning of the albino rabbit's nictitating membrane response. Journal of Experimental Psychology, 1965, 69, 186-192.

BrUNER, A. Facilitation of classical conditioning in rabbits by reinforcing brain stimulation. Psychonomic Science, 1966, 6, 211-212.

Durort, R. H., \& Kimble, G. A. Ready signals and the effect of interpolated UCS presentations in eyelid conditioning. Journal of Experimental Psychology, 1958, 56, 1-7.

Frey, P. W. \& Butle R, C. S. Extinction after aversive conditioning: An associative or nonassociative process? Learning and Motivation, 1977, 8, 1-17.

FrEY, P. W., \& Gavin, W. Overnight incubation of a partially conditioned eyeblink response in rabbits. Animal Learning \& Behavior, 1975, 3, 114-118.

Frey, P. W.. Maisiak, R., \& Dugue, G. Unconditional stimulus characteristics in rabbit eyelid conditioning. Journal of Experimental Psychology: Animal Behavior Processes, 1976, 2, 175-190.

Goodrich, K. P., Ross, L. E., \& Wagner, A. R. Performance in eyelid conditioning following interpolated presentations of the UCS. Journal of Experimental Psychology, 1957, 53, 214-217.

Goodrich, K. P., Ross, L. E., \& Wagner, A. R. Supplementary report: Effect of interpolated UCS trials in eyelid conditioning without a ready signal. Journal of Experimental Psychology, $1959,58,319-320$.

Gormezano, I. Classical conditioning. In J. B. Sidowski (Ed.), Experimental methods and instrumentation in psychology. New York: McGraw-Hill, 1966.

Gormezano, I. Investigations of defense and reward conditioning in the rabbit. In A. H. Black \& W. F. Prokasy (Eds.), Classical conditioning II. New York: Appleton-Century-Crofts, 1972.

Grant, D. A., McFarling, C., \& Gormezano, I. Temporal conditioning and the effect of interpolated UCS presentations in eyelid conditioning. Journal of General Psychology, 1960, 63, 249-257.

Grevert, P., \& Moore, J. W. The effects of unpaired US presentations on conditioning of the rabbit's nictitating membrane response: Consolidation or contingency. Psychonomic Science, $1970,20,177-179$.

Hoehler, F. K., Kirschenbaum, D. S., \& Leonard, D. W. The effects of overtraining and successive extinctions upon nictitating membrane conditioning in the rabbit. Learning and Motivation, 1973, 4, 91-101.

Hoenlen, F. K., \& Thompson, R. F. Effect of the interstimulus (CS-UCS) interval on hippocampal unit activity during classical conditioning of the nictitating membrane response of the rabbit (Oryctolagus cuniculus). Journal of Comparative and Physiological Psychology, 1980, 94, 201-215.

Hull. C. L. Principles of behavior. New York: Appleton-Century, 1943.

KıмBLE, G. A. Hilgard and Marquis' Conditioning and learning. New York: Appleton-Century-Crofts, 1961.

Kimble, G. A., \& Dufort, R. H. The associative factor in eyelid conditioning. Journal of Experimental Psychology, 1956, 52, 386-391 
Kimble, G. A., Mann, L. I., \& Dufort, R. H. Classical and instrumental eyelid conditioning. Journal of Experimental Psychology, 1955, 49, 407-417.

KIMBLE, G. A., \& OST, J. W. P. Influence of unpaired UCS presentations on eyelid conditioning. Psychological Reports, 1961, 9, 239-245.

Leonard, D. W., Fischbein, L. C., \& Monteau, J. E. The effects of interpolated US alone (USa) presentations on classical nictitating membrane conditioning in rabbit (Oryctolagus cuniculus). Conditional Reflex, 1972, 7, 107-114.

LEVINTHAL, C. F. The CS-US interval function in rabbit nictitating membrane response conditioning: Single vs. multiple trials per conditioning session. Learning and Motivation, 1973, 4, 259-267.

LoESs, H. Effect of unpaired UCS presentations on performance in eyelid conditioning. Psychological Reports, 1964, 15, 439-444.

Martin, G. K., Land, T., \& Thompson, R. F. Classical conditioning of the rabbit (Oryctolagus cuniculus) nictitating membrane response, with electrical brain stimulation as the unconditioned stimulus. Journal of Comparative and Physiological Psychology, 1980, 94, 216-226.

McAlliste r, W. R., \& McAllister, D. E. The influence of the ready signal and unpaired UCS presentations on eyelid conditioning. Journal of Experimental Psychology, 1960, 60, 30-35.
Mis, F. W., \& Moore, J. W. Effect of preacquisition UCS exposure on classical conditioning of the rabbit's nictitating membrane response. Learning and Motivation, 1973, 4, 108-114.

Salafia, W. R., Daston, A. P., Bartosiak, R. S., Hurley, J., \& Martino, L. J. Classical nictitating membrane conditioning in the rabbit (Oryctolagus cuniculus) as a function of unconditioned stimulus locus. Journal of Comparative and Physiological Psychology, 1974, 86, 628-636.

Sмгтн, M. C. CS-US interval and US intensity in classical conditioning of the rabbit's nictitating membrane response. Journal of Comparative and Physiological Psychology, 1968, 66, 679-687.

SPENCE, K. W. Learning and performance in eyelid conditioning as a function of intensity of the UCS. Journal of Experimental Psychology, 1953, 45, 57-63.

Spence, K. W., Haggard, D. F., \& Ross, L. E. UCS intensity and the associative (habit) strength of the eyelid CR. Journal of Experimental Psychology, 1958, 55, 404-411.

Trapold, M. A., \& Spence, K. W. Performance changes in eyelid conditioning as related to the motivational and reinforcing properties of the UCS. Journal of Experimental Psychology, 1960, 59, 209-213.

(Received for publication May 15, 1980; revision accepted September 24,1980 .) 